\title{
DO CONTROLE ESTATAL ÀS FORMAS DE RESPONSABILIZAÇÃO: A AUTONOMIA DO PROFESSOR COORDENADOR ${ }^{*}$
}

\author{
MARIA DE FÁtima Barbosa ABdalla** \\ LUANA SERRA Elias TAVARES ${ }^{* * *}$
}

\begin{abstract}
RESUMO: Este texto tem como objetivo refletir sobre o professor coordenador (PC) no contexto do "Programa Ler e Escrever", da Secretaria de Educação do Estado de São Paulo (SEE/SP), buscando compreender as formas de responsabilização e/ou autonomia deste sujeito frente ao controle estatal, tendo como referência os pressupostos teóricos de Foucault, ao discutir o poder disciplinar, e Ball, ao tratar dos efeitos de algumas tecnologias políticas. Os resultados apresentados apontam para três diferentes formas de responsabilização e/ou autonomia, delineando que esta tem limites, exige conhecimento e esforço pessoal; e evidenciam, ainda, que o PC é vítima dos discursos reformistas e objetos da reforma, na medida em que lhe falta um posicionamento crítico que permita questionar, contrapor ou reforçar as propostas contidas nesta política curricular.
\end{abstract}

Palavras-chave: Professor coordenador (PC). Formas de responsabilização e/ou autonomia. Controle estatal. Programa Ler e Escrever.

\section{From STATE CONTROL TO THE FORMS OF ACCOUNTABILITY: THE AUTONOMY OF THE COORDINATING TEACHER}

\begin{abstract}
This text aims at reflecting on the role of the Coordinating Teacher (CT) in the context of SEE/SP'S "Read and Write Program," seeking to understand the forms of accountability and/or autonomy of this subject insofar as state control is concerned. It makes reference to the theoretical assumptions of Foucault, when discussing disciplinary power, and of Ball, in addressing the effects of some political technologies. The results point to three different forms of accountability and/or autonomy, outlining that it has limits and requires knowledge and personal effort. They also show that the CT is the victim of the reformist discourses and objects of reform, in that he or she lacks a critical
\end{abstract}

\footnotetext{
Este texto é uma versão revista e atualizada do trabalho apresentado no IV Seminário de Educação Brasileira (SEB), promovido pelo Centro de Estudos Educação e Sociedade (Cedes), que ocorreu na Universidade Estadual de Campinas (Unicamp), de 20 a 22 de fevereiro de 2013.

* Universidade Católica de Santos (Unisantos). Santos (SP) - Brasil.

*** Universidade Católica de Santos (Unisantos). Santos (SP) - Brasil.

Contato com as autoras: <mfabdalla@uol.com.br>
} 
Do controle estatal às formas de responsabilização: a autonomia do professor coordenador

position enabling him or her to question, counteract or reinforce the proposals contained in this curricular policy.

Key words: Coordinating teacher. Forms of accountability and/or autonomy. State control. Read and Write Program.

\section{Du CONTRÔLE DE L'ETAT AUX FORMES DE RESPONSABILISATION: L'AUTONOMIE DE L'ENSEIGNANT COORDINATEUR}

RÉSUMÉ: Ce texte se présente comme une réflexion sur l'Enseignant/Professeur Coordinateur (PC) dans le contexte du Programme Lire et Ecrire, de la SEE/SP, cherchant à comprendre les formes de responsabilisation et/ou d'autonomie de ce dernier face au contrôle de l'état de São Paulo. Il se réfère aux présupposés théoriques de Foucault, pour discuter le pouvoir disciplinaire, et à Ball pour traiter des effets de certaines technologies politiques. Les résultats présentés indiquent trois différentes formes de responsabilisation et/ou autonomie, en montrant que celle-ci a des limites, qu'elle exige de connaissance et d'effort personnel. Et, mettent également en évidence que le PC est victime des discours réformistes et objets de la réforme, dans la mesure où il lui manque un positionnement critique ce qui nous permet d'interroger, s'opposer ou renforcer les propositions contenues dans cette politique curriculaire.

Mots-clés: Enseignant coordinateur. Formes de responsabilisation et/ou autonomie. Contrôle de l'État. Programme Lire et Ecrire.

\section{Introdução}

$\mathrm{E}$ ste texto tem como objetivo central refletir sobre o professor coordenador (PC) no contexto do "Programa Ler e Escrever", da Secretaria de Educação do Estado de São Paulo (SEE/SP), buscando compreender as formas de responsabilização e/ou autonomia deste sujeito frente ao controle estatal.

Para apresentar o cenário da pesquisa levamos em conta a política educacional da SEE/SP (2007 a 2011), colocando o foco nesse Programa, e as investigações realizadas sobre o PC frente ao seu papel na escola e às diferentes implicações políticas que o envolvem (CASEIRO, 2007; CELEGATO, 2008; LIMA, 2009; ANTUNES, 2010). Ainda, é preciso destacar que as reflexões aqui contidas fundamentam-se em Nóvoa (1991), Gimeno Sacristán (1999a, 1999b, 2000), Contreras (2002) e, especialmente, em Ball $(2005,2008)$ e Foucault $(2002,2007)$.

Tomando como referência esta política de formação continuada de professores, este texto se estrutura em três partes. A primeira coloca o acento no Programa Ler e Escrever, destacando elementos que reforçam o tal "controle estatal", e tece reflexões sobre o papel do professor coordenador, fundamentando-se em alguns pressupostos teóricos (FOUCAULT, 2002; BALL, 2005, 2008). A segunda, ao focalizar os caminhos da pesquisa, centra-se nos resultados obtidos junto a três professoras coordenadoras, 
desvelando o que pensam sobre sua autonomia profissional no âmbito desse Programa. E, por fim, algumas considerações, que trazem à baila questões que poderão se desdobrar em pistas para outras reflexões.

\section{Do "Programa Ler e Escrever": o que se espera do professor coorde- nador?}

O "Programa Ler e Escrever" teve origem na Secretaria Municipal de Educação de São Paulo, por meio da Diretoria de Orientação Técnica (DOT), e instituído, em 2006, a partir da Portaria SME n. 6.328, de 26/09/05 (SÃO PAULO, 2005), revogada pela Portaria n. 5.403/07 (SÃO PAULO, 2007a).

Este Programa foi implantado nas escolas estaduais paulistas a partir de 2007, com a publicação no DOE da Resolução SE - 86, de 19/12/2007 (SÃO PAULO, 2007b), que o instituía, a partir de 2008, no Ciclo I (1ª a $4^{a}$ érie). Sua meta era ver "plenamente alfabetizadas, até 2010, todas as crianças com até 8 anos de idade, matriculadas na rede estadual de ensino, bem como garantir recuperação da aprendizagem de leitura e escrita aos alunos das demais séries/anos do Ciclo I do ensino fundamental" (SÃO PAULO, 2008). Nesta direção, o Programa previa, entre algumas de suas ações: encontros de formação sistemáticos para todos os profissionais envolvidos; recuperação da aprendizagem (Projeto Intensivo no Ciclo-PIC) nas $3^{\underline{a}}$ e $4^{\underline{a}}$ séries; um "aluno pesquisador" nas salas de $1^{\circ}$ ano e de PIC (Bolsa Alfabetização); elaboração e distribuição de materiais didáticos; e acompanhamento institucional sistemático às diretorias de ensino para apoiar o desenvolvimento do trabalho.

A primeira fase deste Programa teve início, em 2007, com iniciativas nas escolas da capital paulista, como a adoção do Bolsa Alfabetização ( $2^{\circ}$ sem./2007) e a formação de professores (2008). Também, no ano de 2008, o mesmo foi ampliado para a Região Metropolitana de São Paulo e, em 2009, para o interior e litoral, a partir do Decreto n. 54.553, de 16/07/2009 (SÃO PAULO, 2009a). Atualmente, este Programa conta, segundo site oficial, com 850 mil alunos, 234 mil professores e mais de 12 mil livros entregues a alunos e professores (SÃO PAULO, 2013).

O que sobressai neste Programa é, certamente, o número de alunos e professores envolvidos, assim como os projetos que se alinham a ele, tal como o Projeto Intensivo no Ciclo-PIC, voltado para a recuperação da aprendizagem. Além disso, é necessário destacar as principais funções propostas para o professor coordenador (PC), no sentido de assessorar a direção da escola: na articulação das ações pedagógicas desenvolvidas; na coordenação dos diferentes projetos, inclusive os de reforço da aprendizagem; na relação escola/comunidade; e executar, acompanhar e avaliar as ações previstas no projeto pedagógico da escola (SÃO PAULO, 2000). 
Por outro lado, a Resolução n. 88, de 19 de dezembro de 2007 (SÃO PAULO, 2007c), ao enfatizar que a coordenação pedagógica se constitui em um dos pilares da atual política, indica como objetivos: ampliar o domínio dos conhecimentos e saberes dos alunos, elevando o nível de desempenho escolar evidenciado pelos instrumentos de avaliação externa e interna; intervir na prática docente, incentivando os professores e visando à superação das dificuldades; e promover o aperfeiçoamento e o desenvolvimento profissional dos professores, com vistas à eficácia e melhoria de seu trabalho.

Após a Resolução n. 88/2007, a SEE/SP lança, a partir de 2008, uma série de documentos apresentando sua proposta curricular (SÃO PAULO, 2008). Dentre as publicações, vale ressaltar o Caderno do Gestor (SÃO PAULO, 2009b), com três volumes, nos quais são apontadas as orientações aos gestores, em especial, ao PC, quanto à implementação da proposta política e curricular para o Ciclo II do ensino fundamental (6 a 9ªnos) e ensino médio, conhecida como "São Paulo Faz Escola".

Dessa forma, é possível perceber o quanto o PC é legitimado como aquele que possui os "olhos visíveis" do sistema, já que usa de um poder disciplinar para controlar os resultados esperados por essa política. Esse controle e/ou poder disciplinar, como diria Foucault (2002), age sobre os sujeitos por meio de instrumentos/técnicas, tais como: a vigilância hierárquica, a sanção normalizadora e o exame.

A vigilância hierárquica pode ser verificada na exigência que é determinada ao PC. Cabe a ele, por exemplo, atuar como observador constante da aprendizagem dos alunos, do trabalho docente e da prática de sala de aula, a fim de prestar contas ao sistema, para alcançar as seguintes metas: todos os alunos de 8 anos plenamente alfabetizados; redução de $50 \%$ das taxas de reprovação da $8^{\text {a }}$ série; redução de $50 \%$ das taxas de reprovação do ensino médio; implantação de programas de recuperação de aprendizagem nas séries finais de todos os ciclos de aprendizagem; aumento de $10 \%$ nos índices de desempenho dos ensinos fundamental e médio nas avaliações nacionais e estaduais (SÃO PAULO, 2009b).

A sanção normalizadora aparece em forma de uma pressão constante exercida pelo sistema sobre o PC e, por consequência, deste sobre o corpo docente. Assim, para se seguir as normas previstas neste Programa, observam-se as pequenas punições aplicadas cotidianamente (prazos, comportamentos, empenho, obediência). E, por fim, o exame, que, segundo Foucault (2002, p. 154), “combina as técnicas da hierarquia que vigia e as da sanção que normaliza", e é aqui determinado pelo sistema ao qual o professor está submetido (sondagens bimestrais, avaliações externas, recebimento de bônus, entre outras), orientando a manutenção ou correção de condutas adotadas.

Esse contexto provém, como diria Ball (2005), dos efeitos combinados de algumas "tecnologias políticas" apontadas como: forma de mercado, performatividade e gerencialismo. 
A forma de mercado contempla a primazia da concorrência, da competitividade e da visibilidade de resultados, por meio da publicização dos índices extraídos de avaliações de larga escala e que passaram a fazer parte do cenário educacional brasileiro. Já o gerencialismo tem sido o principal meio de entrada da lógica da reforma neoliberal, que pretende deixar na mão do "gerente" a tarefa de incutir em seus pares a responsabilidade pelo funcionamento e bem-estar das organizações, para que se torne possível colocar em prática uma política de metas que visa a resultados. Finalmente, a performatividade pode ser entendida com foco na performance dos sujeitos envolvidos no sistema. Assim, as palavras de ordem são: desempenho, eficácia e mensuração. Há, neste sentido, uma eterna busca de se alcançar o melhor resultado, como se ele fosse possível apenas por meio do bom desempenho do sujeito.

Esse é o modo encontrado pelo sistema para colocar em prática uma lógica de controle tida como "perfeita", sob o olhar da administração central, uma vez que considera que, por ter o controle de todos os mecanismos e de tudo o que acontece, nada fugirá ao planejado. Ball (2008) e outros colaboradores (BRAUN; BALL; MAGUIRE, 2010) trazem a ideia de que as políticas não são implementadas, mas encenadas ou traduzidas em ato pelos atores/sujeitos, que agem como objeto/instrumentos das políticas, a partir da complexa interpretação dos discursos encontrados nos documentos que as definem.

O que essas tecnologias políticas promovem, com todo o seu poder regulador, na verdade, acaba se tornando uma autorregulação exercida pelos sujeitos sobre eles mesmos e sobre seus pares. Além disso, as políticas também são feitas e pensadas pelos sistemas educacionais, em contextos ideais, em lógicas infalíveis, que não contam com as subjetividades e condições que definem os contextos reais das escolas. Nas palavras de Ball, Maguire e Braun (2012), tanto quem elabora as políticas, quanto quem as executa tendem a buscar a melhor condição possível para sua implementação.

Cabe, aqui, sugerirmos uma relação entre as tecnologias políticas de Ball (2005) e as técnicas/instrumentos, utilizados como mecanismos das relações de poder, investigados por Foucault (2002). Assim, para a forma de mercado, de Ball (2005), temos as relações de poder disciplinar, de Foucault (2002), como elemento presente na forma de pensar o sistema educacional como mercadoria, uma vez que a política prega e busca a competitividade e os melhores resultados. Para o gerencialismo (BALL, 2005), a vigilância hierárquica e a sanção normalizadora (FOUCAULT, 2002), já que os atores são vistos como peças-chave do sistema para garantir metas. Finalmente, para a performatividade (BALL, 2005), o exame (FOUCAULT, 2002) é a técnica usada para medi-la, ou seja, para mensurar o quanto os sujeitos desempenham bem seus papéis como mediadores desse processo. Parece-nos, assim, que o que está em jogo é o quanto se precisa, de fato, promover espaços de reflexão, questionamento, confronto, negociação e estudo sobre como transformar práticas escolares com vistas à mudança desejada. 
Ora, se é condição que o PC não seja um reprodutor de ideias, mas sim que atue de maneira criativa, questionadora, reflexiva, temos uma contradição posta entre o discurso político e o discurso pedagógico: ambos oficiais.

Além disso, se recuperarmos a trajetória das discussões sobre formação continuada, que se configurou em diferentes formatos, desde os mais estruturantes e tradicionais, até os mais construtivos e reflexivos (NÓVOA, 1991), interessa-nos, aqui, entender de que modo, com quais condições e limites/potenciais esse modelo de formação continuada, posto e exigido ao PC da SEE/SP, configura o seu papel como formador de professores no contexto deste Programa.

Na esteira dessa discussão, é preciso lembrar que as reformas educacionais exigem, por consequência, sujeitos igualmente reformados. Com isso, as inovações trazidas com novos programas estabelecem novos padrões de se fazer/pensar a educação, assim como configuram novos comportamentos, atitudes e representações sociais (MOSCOVICI, 1985). Nesta perspectiva, vale indagar como o PC pode articular, na formação de professores, dois polos aparentemente tão distintos: a reprodução de modelos prescritos e a mobilização do questionamento e da reflexividade.

Ousamos sugerir que, embora no discurso oficial, a formação continuada seja defendida e incentivada como um espaço de mediação de saberes e reflexividade crítica sobre as práticas pedagógicas, entre outros aspectos; no discurso político, também oficial, a mesma formação funciona como um dos modos de controle que se enquadrariam naquilo que Ball (2005) chamou de gerencialismo. Isso porque ela coloca na mão dos gestores, no caso dos PCs, a responsabilização (ou "formas de responsabilização" e/ou "autonomia") pelo enquadramento do pensamento do grupo docente no "pacote didático" imposto pelo sistema e na prestação de contas quanto à melhoria dos resultados escolares.

Isso nos parece ser o ponto nevrálgico da lógica imposta por este Programa, na medida em que se espera do PC, na assunção do seu papel de formador de professores e tendo de gerenciar os problemas, que atue de forma autônoma e criativa na condução desse ofício. Desde que, é claro, não transgrida o que é preconizado.

\section{Dos caminhos da pesquisa para desvendar as formas de responsa- bilização/autonomia}

Na 1a fase, realizou-se uma pesquisa exploratória com 75 PCs das Diretorias de Ensino de Itaquaquecetuba, Mogi das Cruzes e Suzano. Porém, este texto contempla resultados da $2^{\underline{a}}$ fase, que envolveu três PCs em escolas estaduais pertencentes a Diretorias de Ensino do Litoral de SP: uma de Santos e duas de São 
Vicente. São professoras efetivas, formadas em Pedagogia, com experiência de 5 a 25 anos e trabalham apenas no Ciclo I.

Foram analisadas as pautas formativas utilizadas nas reuniões de formação destas professoras e, a partir disso, elaboramos um roteiro de questões para a realização de entrevistas semiestruturadas. A intenção era investigar uma possível ausência/presença de autoria dessas profissionais na atuação como formadoras de professores. Buscávamos, ainda, levantar o grau de consciência destas PCs sobre a responsabilização (ou irresponsabilização) que lhes é conferida pelo sistema educacional, quando colocadas para responder pelo sucesso da aprendizagem dos alunos e por boas práticas docentes.

Com a análise das pautas das PCs, perguntávamos, em especial, de que autonomia estávamos falando e, principalmente, se uma autonomia "plena" seria possível em qualquer contexto pedagógico. Ou seja, seria a escola um espaço aberto a essa autonomia do PC, independentemente das barreiras impostas pela política educacional vigente?

Gravamos e transcrevemos as entrevistas e usamos, como técnica de tratamento dos dados, a análise de conteúdo de Bardin (2011). Partimos do pressuposto de que a liberdade destinada ao professor (e ao PC) está circunscrita a um espaço bastante restrito, a partir de regras bem definidas e por meio de uma acomodação às condições da realidade que se impõem e que delineiam determinadas "formas de responsabilização" e/ou de autonomia.

Tendo em vista estas considerações, este texto privilegia parte dos resultados da pesquisa, que diz respeito à autonomia no profissionalismo dessas PCs frente ao "controle estatal", tendo em vista o desenvolvimento do Programa em questão. Isso implica avaliar como estas PCs assumem "formas de responsabilização", ou seja, espaços de autonomia que, conforme as cenas descritas, a seguir, se diferenciam e, ao mesmo tempo, se complementam.

\section{Cena 1: A autonomia tem limites}

E: E como você prioriza conteúdos [para a formação dos professores]?

S1: Por isso que eu falo da autonomia. Eles não impõem... e você acaba tendo que selecionar algumas coisas. Verifico o que eles têm mais dificuldades, o que eles estão mais errando, tanto eles como eu, do que eles estão precisando de mais discussão, de conhecimento teórico para poder ter uma atuação na sala de aula. [...].

E: E isso tem que aparecer na escola ou você poderia optar por não trabalhar com isso? Onde fica a questão da imposição, então?

S1: Tem que aparecer na escola. [...] e, nessas formações, eles estão trabalhando, justamente, com coisas que eles observam que não é trabalhado na escola. [...]. 
Do controle estatal às formas de responsabilização: a autonomia do professor coordenador

E: E de onde eles tiram a informação do que se precisa na escola? Por que eles geralmente acertam? Já pensou nisso?

S1: Eu imagino que seja por conhecer a concepção do professor, que o professor não é aquele camarada que busca? Eles fazem algumas visitas na escola toda semana e as professoras têm uma rotina semanal onde elas têm que colocar o que vão trabalhar durante a semana e aquilo é também um indicador do que está sendo ou não trabalhado. (Grifos nossos)

Como percebemos, existe, na fala desta professora (S1), uma defesa, a priori, da ideia de que a autonomia existe e que as imposições não são feitas pelo sistema. Segundo S1, a condição para um conteúdo ser eleito para a formação dos professores é que seja detectada sua necessidade quanto àquilo que considera que seus professores precisam "aprender". Todavia, ela nos coloca que tudo o que é trazido pela formadora é necessidade da escola, pois "eles" sabem (por experiência e por controle) o que, de fato, os professores estão precisando.

Ao usar o pronome "eles", quando S1 refere-se ao sistema, parece-nos trazer uma ideia subjacente de algo indefinido e/ou indeterminado. Ou seja, seria como se tais decisões não fossem pensadas por pessoas que, a partir de determinado lugar hierárquico, decidem por aqueles que não têm condições ou não estão aptos a fazê-lo. Isso nos revela, também, a ideia da fabricação de corpos dóceis, pela via das tecnologias que naturalizam o processo disciplinar, como diria Foucault (2002).

Com efeito, pela sofisticação dessa tecnologia, os sujeitos vão se enxergando dentro de uma rede disciplinar que se torna invisível para eles, a ponto de configurarse como natural e necessária. Diríamos que, de um lado, existem os mecanismos do gerencialismo, como afirmam Maguire e Ball (2011, p. 179), impondo "procedimentos gerenciais que pretendem simplificar e acelerar o processo decisório" e que acabam por minimizar a participação dos sujeitos envolvidos; e, de outro lado, verifica-se o quanto estes sujeitos encaram o controle, a regulação e a disciplina como elementos naturais e inerentes ao processo educacional.

Isso significa que o PC tem uma suposta autonomia para fazer suas escolhas formativas. E o que vem a ele como uma demanda de trabalho, já pensada por terceiros, precisa ser acatado, pois sempre será pertinente às reais necessidades de sua escola. Porém, vale lembrar o que Contreras (2002, p. 181) postula, quando diz que: "[...] tal autonomia é enganosa. O ensino entendido como aplicação técnica, como prática dirigida à obtenção de resultados ou produtos previamente definidos, não é uma prática criativa, e sim apenas reprodutiva $[\ldots]$ "..

Assim, há duas questões a serem enfrentadas. A primeira tem a ver, conforme Ball (2011, p. 46), com "a forma como nós tornamos as políticas encarnadas", a ponto de somente reproduzi-las, sem, de fato, tecer uma reflexão mais crítica. A segunda, decorrente disso, diz respeito ao quanto se reconhece (ou não) o peso do controle 
estatal no delineamento dos limites da autonomia daqueles sujeitos envolvidos pela circulação das políticas institucionalizadas.

Além disso, quando relegados a um plano em que se excluem os sujeitos do processo decisório sobre as ações educativas realizadas na escola, dificilmente conseguimos a adesão e o sentimento de pertença dos quais nos falam Placco, Almeida e Souza (2011). O que percebemos, na fala de S1, é que esse espaço não é concebido como uma possibilidade de pertencimento; talvez isso ocorra por falta de emancipação crítico-cultural. Tudo isso reforça, então, que a autonomia tem muitos limites...

\section{Cena 2: A autonomia exige conhecimento}

E: E você acha que as professoras estão satisfeitas com esse trabalho?

S2: [...] acredito que elas sentem isso e gostam do material, quando entendem a proposta...

E: E como formadora de professores, você sente que tem liberdade em fazer as escolhas necessárias ou sente-se controlada, cerceada por alguém, pela Diretoria, pela formadora ou pelos índices?

S: Quanto a isso, eu acho que tem liberdade sim. [...] a Diretoria de ensino sempre está na escola; eles leem as pautas, veem o nosso trabalho...

E: E você não sente isso como uma cobrança?

S: Tem o olhar da cobrança também, mas por mais que o olhar da escola tenha essa diferenciação de ideias, a diretora dá muita autonomia. Eles zêm olhar seu trabalho, mas você também tem autonomia naquilo que tá fazendo. Eu vejo isso! [...]. Ou, às vezes, sou eu mesmo que sugiro outra forma de trabalhar aquele mesmo assunto, então eu vejo que tem autonomia. Agora, eu uso muito da formação porque eu estou aprendendo e não tenho o domínio de todo esse assunto. Então, por isso a formação me dá um suporte muito grande!

E: Você acha que mesmo trabalhando em um programa que é institucional, obrigatório [...], você tem espaço para uma atuação como formadora autônoma?

S2: Sim, eu acredito que sim. Veja, se eu tivesse toda a propriedade e o conhecimento sobre o programa e sua concepção, eu teria mais liberdade para fazer minhas escolhas [...]. (Grifos nossos)

No excerto da entrevista de S2, observamos outra ideia: a de que autonomia é alcançada com mais conhecimento. Essa nos pareceria uma ideia aceitável, caso estivéssemos falando de conhecimento em linhas gerais, pois é ele quem nos dá a ferramenta essencial ao discernimento necessário para fazer nossas próprias escolhas.

Contudo, o que nos parece premente, na fala de S2, é um ponto de partida que considera o conhecimento técnico, específico, sobre um determinado objeto. Parte de um pressuposto de que autonomia é algo indissociável de domínio especializado sobre o assunto. Não compartilhamos dessa posição, por entendermos que isso seria reduzir demais o que se pretende como autonomia no profissionalismo. 
Explicitando melhor: parece-nos que a preocupação aqui é alcançar ainda mais os propósitos impostos pelas políticas educacionais, a fim de gerar o que Ball (2011) registra como performance, no âmbito da tecnologia da performatividade. Nesse caso, estamos falando, basicamente, de resultados definidos por metas e incentivados por mecanismos de controle, que estão no cerne desse Programa e que envolvem a autorregulação e a competição entre os sujeitos.

Para nós, a autonomia é mais do que assumir conhecimentos específicos no âmbito de um Programa, mas ela se legitima na ação prática que se constrói no exercício diário de quem busca soluções para os conflitos cotidianos, encontrando-as colaborativamente entre seus pares. Esperar pelo momento em que teremos todas as respostas necessárias é ter uma visão muito idealizada sobre o cotidiano escolar.

Em contrapartida, também, não acreditamos que tudo deva estar somente nas mãos do professor; uma vez que toda prática que se pretenda, reflexiva e emancipatória, acontecerá sempre considerando o contexto social na qual está inserida. Entendemos a autonomia não como um bem pessoal, mas como uma conquista coletiva, em prol de toda a ação que se pratica. Mas como alcançá-la quando os limites de atuação são tão definidos?

Gimeno Sacristán (2000, p. 168) nos faz pensar que “[...] a autonomia sempre existe, mas suas fronteiras também". Essa consciência da parcialidade da autonomia é importante para que se vislumbrem os horizontes onde se pretende chegar.

Entendemos, então, que um dos elementos que impõe certa parcialidade à autonomia é a ação política. Quando os professores são excluídos do processo decisório sobre suas ações pedagógicas e seus únicos interlocutores são a política e os aparelhos da administração, não sobra muito para essa relação a não ser desobediência, engodo, acriticidade e pouca autonomia (CONTRERAS, 2002).

Pensar da forma como apresentada por S2 é, de certa maneira, retrato de um produto do discurso implementado por essa política educacional, que determina os modos de ser e de atuar como profissional. Nesse envolvimento ideológico, instala-se uma espécie de miopia que faz com que o sujeito entenda que há liberdade e autonomia, mesmo quando tudo já está previamente definido. E, nesse sentido, a autonomia como conhecimento reforça a responsabilização dos indivíduos pelos resultados institucionais obtidos (ou a serem obtidos), ou melhor, aqueles que o sistema espera obter.

Assim, parece-nos que o que é entendido como uma prática autônoma reduz-se ao como proceder diante de uma ação que já foi pensada. É como se o limite ou a fronteira da autonomia fossem restritos ao "toque pessoal" de cada PC e, garantindo tal personalidade à ação, a autoria já estaria, por consequência, também garantida. 
Dessa maneira, o processo de formação na escola talvez esteja reforçando a ideia presente, na fala de S2, de que a autonomia só será possível quando alcançado o lugar de quem já conhece tudo sobre o Programa: da concepção teórica às estratégias docentes. Para quem ainda não chegou lá, resta seguir o que "seu mestre mandar". Sem a pretensão de esgotar a discussão sobre autonomia, partamos, então, para o trecho referente ao S3, no qual decidimos usar o tema "a autonomia como esforço pessoal".

\section{Cena 3: A autonomia como esforço pessoal}

\section{E: Qual você considera ser o espaço de sua autonomia?}

S3: Vem uma demanda de trabalho e tenho liberdade para fazer adaptações dele com os dados da minha escola, justamente para as professoras terem a visão de como estão nossos alunos.

E: E de onde surgiu esse conteúdo, por exemplo?

S3: Essa escolha não foi minha. Temos reunião com a formadora da equipe central e temos de apresentar essas situações a ela.

S3: Não acho que sou controlada, nem limitada. Eu consigo seguir, mas já fui melhor. O tempo foi passando... Às vezes, falo para mim mesmo que eu tenho que mudar, tipo assim: "alguém está te vencendo". (Grifos nossos)

No primeiro trecho selecionado, destacamos uma defesa muito próxima à realizada pelo S2, no sentido de entender a autonomia como o espaço "permitido" para as adaptações em cima do que é proposto. Já, no segundo, observamos uma aproximação com S1, quando, contraditoriamente, após afirmar que existe autonomia em seus atos, aponta que nem todas as escolhas são feitas por ela, mas a partir de uma demanda imposta de fora. Finalmente, nesse terceiro trecho, aparece-nos uma nova ideia: a de que a autonomia pressupõe a não desistência, o não "deixar-se vencer".

Nesta cena 3, a PC inicia dizendo que não se sente controlada, mas que já conseguiu "seguir mais", que já foi melhor. Entendemos, aqui, que ela defende que sempre realizou uma prática na qual seguia o princípio de não ser controlada, de lutar contra aquilo que não lhe parecia adequado. Contudo, em seguida, aponta o tempo - essa PC já tem mais de 25 anos de trabalho na educação - como um fator que, de alguma maneira, fez com que ela perdesse aquela primeira identidade de resistência, lembrada, inclusive, com saudosismo.

Nessa lembrança, parece que ela retoma a importância de não se deixar abater, não se deixar vencer. Aqui nos questionamos: quem ou o que a estaria vencendo?

Considerando o contexto de sua entrevista, fica-nos presente a observação de que é preciso, para atuar como PC, ser persistente e enfrentar, diariamente, conflitos e tensões que acabam enfraquecendo a ação desse sujeito na escola. 
Tais conflitos aparecem de todos os lados: do sistema, dos órgãos administrativos, da repressão dos índices, da direção da escola, dos professores, de pais de alunos e, também, do próprio sujeito. Nessa permanente pressão, ele acaba entrando em uma crise de desmotivação que, muitas vezes, só é percebida ao longo dos anos, quando, assim como nossa terceira professora que olha para trás, percebe que alguma coisa mudou nela mesma.

Parece-nos, então, que os efeitos da performatividade ou da "luta pela visibilidade" (BALL, 2005, p. 548), enfrentada pelos gestores, acabam recaindo sobre eles próprios, na medida em que, como afirma Ball (2011, p. 28), “[...] a tarefa e o dever do gerenciamento são não mais restritos a autorizar e impor regras e procedimentos, mas a determinar como os empregados deveriam pensar e sentir sobre o que produzem" (grifos do autor). Nesse sentido, percebemos o quanto o papel do PC torna-se contraditório, pois, ao mesmo tempo em que ele deve constituir-se como um pilar que sustenta o discurso da reforma, ele também o questiona, na medida em que discute comportamentos, discursos e representações produzidos por essas políticas educacionais e curriculares.

O tempo também vai revigorando uma espécie de irresponsabilização, como indica Gimeno Sacristán (1999a), no qual o sujeito vê-se impossibilitado de compatibilizar suas ideias com a realidade vivenciada, diariamente, em seu cenário profissional, e por não poder responder pelas decisões tomadas a priori e a despeito de seu posicionamento profissional.

O que se nota, ainda, apesar de todo um "esforço pessoal", em que o próprio sujeito se "autoexamina", "autodisciplina" e se "autopune", como diria Foucault (2002), é o desvirtuamento da autonomia no profissionalismo desses sujeitos.

Com essas reflexões postas, pensamos que pudemos abarcar uma visão daquilo que as PCs consideram como autonomia, mas que, no nosso entender, configura-se muito mais como uma autonomia aparente do que como uma autoria genuína. Consideramos, também, que nenhuma mudança educativa é neutra, nenhuma ação nesse sentido é despida de princípios políticos e ideológicos. Ter em mente o que está subjacente a tais mudanças é condição para a reivindicação de participação em tal processo, para a determinação das formas de responsabilização e/ou autonomia que levam às formas de ser e estar na profissão docente.

\section{Considerações finais}

A pesquisa nos mostrou a relação de poder que a política insere nos sistemas educacionais, de maneira capilarizada, não só entre secretarias de educação e suas instituições escolares, bem como dentro das próprias escolas, uma vez que a lógica 
mercadológica da educação promove sujeitos que se autorregulam e que competem mutuamente o tempo inteiro. E se isso não bastasse, não lhes sobra alternativa a não ser adequar-se a esse pressuposto, pois a publicização dos índices de competência e eficácia das instituições pune ou beneficia, inclusive financeiramente, os sujeitos envolvidos e responsabilizados por tais resultados.

Ao pensar nessa responsabilização (accountability, conforme BALL, 2005) dos professores, é imperativo que pensemos no que nos traz Gimeno Sacristán (1999b, p. 75) sobre o princípio da irresponsabilização relativa dos docentes, uma vez que, se partimos do pressuposto de uma possível incompatibilidade entre suas ideias e a realidade que se impõe, os professores, por mediarem "[...] quase todos os processos pedagógicos, não deixam de ser reprodutores e veículos de outras determinações da prática".

Ficou-nos evidente, então, a defesa por tal autonomização e/ou "formas de responsabilização" dos profissionais nos discursos oficiais, na medida em que a adoção de tais pedagogias "[...] partilha[m] do pressuposto de uma oposição entre as estruturas de poder e dominação, de um lado, e a ação autônoma e livre do indivíduo ou grupo, de outro", conforme aponta Silva (1998, p. 9-10). Como se isso fosse uma opção profissional, o sistema parece relegar aos sujeitos a escolha entre tomar a frente ou não dos processos decisórios nos quais suas ações estão envolvidas. Ainda, na esteira do pensamento de Gimeno Sacristán (1999a, p. 65), significa considerarmos que, ao colocar-se nessa posição "democrática" de dar, aos seus profissionais, a opção de escolha pela autonomia, ficamos "[...] condenados a ver os docentes como 'deformadores' da bondade estabelecida nas propostas ao explicar os inevitáveis fracassos".

Com efeito, como vítimas dos discursos reformistas e objetos da reforma, estes sujeitos parecem acreditar numa autonomia que lhes é concedida pelo próprio sistema, como se uma prática autônoma pudesse ser permitida ou outorgada pelo outro. Não podem, nem lhes parece necessário, lutar contra as amarras impostas pelas relações de poder que se constituem no sistema: ou porque não podem fazer frente a essa opressão e/ou porque, de tão natural, ela nem é mais percebida por tais sujeitos.

Nas falas das PCs, encontramos afirmações categóricas de crença em realizarem um trabalho de verdadeira autoria, entendendo que o espaço das "adequações" das práticas pedagógicas, permitidas pelo Programa, seja o suficiente para a garantia de tal ação. Não admitem, assim, a existência de qualquer espécie de controle, mesmo afirmando, simultaneamente, que precisam prestar contas (em várias instâncias e sobre diferentes aspectos) do trabalho realizado. Sob o seu olhar, o sistema investe em sua autonomia profissional e lhes garante condições de executar um trabalho de autoria nas escolas. 
Nessa perspectiva, faz sentido pensarmos o quanto essa visão de que os discursos dominantes constituem as práticas é ignorada pelos PCs, quando estes refletem sobre sua ação. Então, fica-nos evidente como, independente das contribuições teóricas que qualquer programa ofereça aos sujeitos (e acreditamos que realmente oferece), falta-lhes um posicionamento crítico que permita questionar, contrapor ou, ainda, reforçar tal discurso como resultado de uma escolha profissional e não meramente como uma única alternativa restante. Entretanto, se entendermos que os discursos pedagógicos representam interesses políticos, não há como desvincularmos deles as relações de poder subjacentes.

Parece-nos que tais processos individuais é que se encontram, contudo, em estado de sonolência ou hibernação, embora tenhamos a clareza de que as entrevistas não nos permitem capturar toda a realidade desses profissionais, o programa curricular e as relações que se estabelecem no cenário educativo.

Sem dúvida, tivemos a oportunidade de nos depararmos com um complexo sistema de relações que fazem um programa institucional funcionar e "controlar" as múltiplas "formas de responsabilização" e/ou "autonomia" dos sujeitos que vivem a política curricular de uma rede de ensino. Além disso, constatamos aspectos importantes que definem, conformam e limitam a atuação dos profissionais da educação dentro do cotidiano escolar. Todavia, é preciso destacar, ainda, como diria Foucault (2007, p. 535), que “[...] não se trata aí de afirmações, quando muito de questões às quais não é possível responder; é preciso deixá-las em suspenso lá onde elas se colocam, sabendo apenas que a possibilidade de as colocar abre, sem dúvida, para um pensamento futuro".

\section{Referências}

ANTUNES, M.E.G. A coordenação pedagógica e as contribuições para a formação de professores alfabetizadores. 2010. 197f. Dissertação (mestrado em Educação) - Universidade do Oeste Paulista, Presidente Prudente.

BALL, S.J. Profissionalismo, gerencialismo e performatividade. Cadernos de Pesquisa, São Paulo, v. 35, n. 126, p. 539-564, set./dez. 2005.

BALL, S.J. The education debate. London: Policy Press, 2008.

BALL, S.J. Sociologia das políticas educacionais e pesquisa crítico-social: uma revisão pessoal das políticas educacionais e da pesquisa em política educacional. In: BALL, S.J.; MAINARDES, J. (Org.). Políticas educacionais: questões e dilemas. São Paulo: Cortez, 2011.

BALL, S.; MAGUIRE, M.; BRAUN, A. How schools do policy: policy enactments in secondary schools. London and New York: Routledge, 2012. 
BARDIN, L. Análise de conteúdo. 2. reimp. São Paulo: Edições 70, 2011.

BRAUN, A.; BALL, S.J.; MAGUIRE, M. Policy enactments in the UK secondary school: examining policy, practice and school positioning. Journal of Education Policy, London, v. 25, n. 4, p. 547-560, jul. 2010.

CASEIRO, L.L. A atuação do professor coordenador pedagógico no desenvolvimento profissional dos docentes. 2007. 160f. Dissertação (mestrado em Educação) - Universidade do Oeste Paulista, Presidente Prudente.

CELEGATTO, C.A. Formação em serviço: significado do "Programa Ler e Escrever" numa escola municipal de ensino fundamental. 2008. 280f. Dissertação (mestrado em Educação) - Faculdade de Educação da Universidade de São Paulo, São Paulo.

CONTRERAS, J. A autonomia dos professores. São Paulo: Cortez, 2002.

FOUCAULT, M. Vigiar e punir: nascimento da prisão. 25. ed. Trad. Raquel Ramalhete. Petrópolis: Vozes, 2002.

FOUCAULT, M. As palavras e as coisas. 9. ed. São Paulo: Martins Fontes, 2007.

GIMENO SACRISTÁN, J. Poderes instáveis em educação. Trad. Beatriz Affonso Neves. Porto Alegre: Artmed, 1999a.

GIMENO SACRISTÁN, J. Consciência e acção sobre a prática como libertação profissional dos professores. In: NÓVOA, A. Profissão professor. Porto: Porto, 1999b.

GIMENO SACRISTÁN, J. O currículo: uma reflexão sobre a prática. 3. ed. Porto Alegre: Artmed, 2000.

LIMA, M.N. O professor coordenador da rede oficial de ensino do estado de São Paulo: um estudo de caso sobre a (re)construção de sua ação pelo cotidiano. 2009. 92f. Dissertação (mestrado em Educação Escolar) - Faculdade de Ciências e Letras, Universidade Estadual Paulista, Araraquara.

MAGUIRE, M.; BALL, S.J. Discursos da reforma educacional no Reino Unido e nos Estados Unidos e o trabalho dos professores. In: BALL, S.J.; MAINARDES, J. Políticas educacionais: questões e dilemas. São Paulo: Cortez, 2011. p. 175-192.

MOSCOVICI, S. (Org.). Psicologia social, I: Influência y cambio de actitudes. Indivíduos y grupos. Barcelona: Paidós, 1985.

NÓVOA, A. (Org.). Formação contínua de professores: realidade e perspectivas. Portugal: Universidade de Aveiro, 1991.

PLACCO, V.M.N.S.; ALMEIDA, L.R.; SOUZA, V.L.T. O coordenador pedagógico e a formação de professores: intenções, tensões, contradições. São Paulo: Fundação Vitor Civita, 2011. 
SÃO PAULO. Secretaria de Educação do Estado de São Paulo. Resolução SE n. 35, de 7 de abril de 2000. Dispõe sobre o processo de seleção, escolha e designação de docente para exercer as funções de Professor Coordenador, em escolas da rede estadual de ensino e dá providências correlatas. Disponível em: <http://lise.edunet. sp.gov.br/paglei/resolucoes/35_2000.HTM>. Acesso em: 11 nov. 2012.

SÃO PAULO. Secretaria Municipal de Educação. Portaria SME n. 6.328, de 26 de setembro de 2005. Implementa o Programa "Ler e Escrever- Prioridade na Escola Municipal" nas Escolas Municipais de Ensino Fundamental - EMEFs e Escolas Municipais de Ensino Fundamental e Médio - EMEFMs. Disponível em: <http://www3. prefeitura.sp.gov.br/cadlem/secretarias/negocio>. Acesso em: 13 maio 2012.

SÃO PAULO. Secretaria Municipal de Educação. Portaria SME n. 5.403, de 16 de novembro de 2007a. Reorganiza o Programa "Ler e Escrever- Prioridade na Escola Municipal" nas EMEFs, EMEFMs e EMEEs. Disponível em: <http://portalsme.prefeitura. sp.gov.br/Projetos/supervisao/An>. Acesso em: 16 nov. 2012.

SÃO PAULO. Secretaria de Educação do Estado de São Paulo. Resolução SE n. 86, de 19 de dezembro de 2007b. Institui, para o ano de 2008, o Programa "Ler e Escrever", no Ciclo I das Escolas Estaduais de Ensino Fundamental das Diretorias de Ensino da Coordenadoria de Ensino da Região Metropolitana da Grande São Paulo. Disponível em: <http://siau.edunet.sp.gov.bt/ItemLive/arquivos/86_07.HTM?T>. Acesso em: 15 jun. 2012.

SÃO PAULO. Secretaria de Educação do Estado de São Paulo. Resolução SE n. 88, de 19 de dezembro de 2007c. Dispõe sobre a função gratificada de Professor Coordenador. Disponível em: <http://siau.edunet.sp.gov.bt/ItemLive/arquivos/88_07.HTM>. Acesso em: 15 ago. 2012.

SÃO PAULO. Secretaria de Educação do Estado de São Paulo. Documento de Apresentação do Programa Ler e Escrever, julho de 2008. Disponível em: <http:// lereescrever.fde.sp.gov.br/SysPublic/Home.aspx>. Acesso em: 5 fev. 2012.

SÃO PAULO. Secretaria de Educação do Estado de São Paulo. Resolução n. 66, de 21 de agosto de 2009a. Dispõe sobre a implementação do disposto no Decreto n. 54.553, de 15 de julho de 2009, que institui o Programa de Integração Estado/Município para o desenvolvimento de ações educacionais conjuntas. Disponível em: <http:// lereescrever.fde.sp.gov.br/Handler/UplConteudo.ashx?jka>. Acesso em: 8 jun. 2012.

SÃO PAULO. Secretaria de Educação do Estado de São Paulo. Caderno do Gestor: gestão do Currículo na Escola. São Paulo: SEE, 2009b. Disponível em: <http://www. rededosaber.sp.gov.br/portais/Protals/18/arquivos/>. Acesso em: 8 jun. 2012.

SÃO PAULO. Secretaria de Educação do Estado de São Paulo. Fundação para o 
Desenvolvimento da Educação/FDE. Site do Programa Ler e Escrever. Disponível em: <http://lereescrever.fde.sp.gov.br/SysPublic/Home.aspx>. Acesso em: 10 jun. 2013.

SILVA, T.T. Liberdades reguladas: a pedagogia construtivista e outras formas de governo do eu. 2. ed. São Paulo:Vozes, 1998.

Recebido em 1 de julho de 2013.

Aprovado em 5 de novembro de 2013. 
